\title{
Giving meaning to the stark facts of breast cancer
}

\author{
Not Done Yet: Living Through Breast \\ Cancer \\ Laurie Kingston \\ Women's Press; 2009. \\ 263 pp $\$ 23.95$
}

$\mathrm{H}$ aving breast cancer is an intense experience and many diagnosed women are compelled to tell their story using the medium of the day. Novelist Fanny Burney's letter to her sister, written in 1811, describing the removal of her breast without anesthetic (by the same surgeon who treated Napoleon) may be the most riveting account of a mastectomy on record. ${ }^{1}$ In the last century, legions of breast cancer patients found their outlets in magazine articles, newspaper accounts, books and film or video.

Laurie Kingston, a patient of the new millennium, started a blog. Crossing the old-fashioned diary with a personal website, a blog affords intimate glimpses into an ongoing life, with its mix of daily routine and startling drama - and anyone linked to the blogosphere can follow along. Not Done Yet compiles selected blog entries beginning in January 2006, a month after

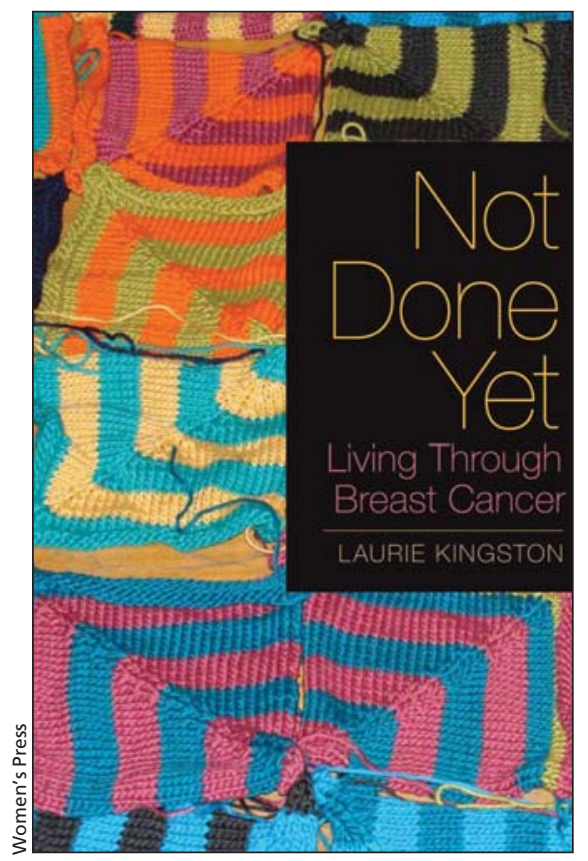

Lauries. Diagnosed at age 38, Kingston has 2 sons (then 2 and 7), a caring husband and a public-sector union job in Ottawa that she loved, but had to leave. Her treatments are typical for a patient in a large Canadian centre: a mastectomy followed by radiation and chemotherapy, supplemented by drugs to combat treatment-induced nausea and anemia. After the cancer

\section{"Don't look horrified when I tell you I have metastatic breast cancer..."}

Kingston's diagnosis, and continuing to February 2008, more than a year after she learned that the cancer had metastasized to her liver.

A physician who treats breast cancer patients might wonder what this blog-cum-book could offer a busy professional whose daily practice likely holds its own heartbreaking quota of spread she began treatments with trastuzumab (Herceptin) and vinorelbine, again with a complement of drugs to alleviate side effects.

However, Kingston's book provides the detail and emotional shadings that give meaning to these stark, exterior facts. The honest telling of a singular story weaves the experience of cancer into the whole cloth of a life, reworked after a devastating rupture. She vividly integrates events and see-sawing emotions, as in this entry:

Boy Herceptin is a trip. One moment I was fine and the next I was flopping around like a fish, with my teeth clattering against my jaw. This lasted for several minutes. It was one of the most bizarre experiences of my life. [p 136]

Health researchers once dismissed such accounts as anecdotes, of little significance to the scientific community, but lay knowledge of medical phenomena is gaining recognition as having its own validity, complementing (and sometimes contesting) knowledge accrued through scientific methods. Science searches for the universal while individual experience provides a localized understanding, enriched by complex social networks. ${ }^{2}$

Research into "lay knowledge" has demonstrated that lay people have knowledge of their own bodies ... they have knowledge of how their bodies react to medication ... and they have knowledge of the situation in which they live. ... [B]y virtue of conceiving the experiment beyond the controlled environment of laboratory, the social situation becomes the site of lay knowledge, an expertise that arises from direct experience of the situation at hand. ${ }^{2}$

From this perspective, Kingston's book is a prime example of lay expertise derived from the quotidian realities of a contemporary Canadian breast cancer patient. Central to her world are her family and friends, but she soon adds her treatment team, her treatments, and a whole new community of bloggers and blog-readers who share in her altered life and celebrate her determination to document it. Her patient's-eye view vividly captures the experience of 
the treatment repertoire, from the classics like doxorubicin (the "Red Devil") to docetaxel, trastuzumab (Herceptin) and filgrastim (her response to injecting the latter drug into her abdomen after practising on an orange: "How cool is that?"). Eventually, her extreme reactions to trastuzumab subside and her liver functions gradually return to normal.

By the end of the book she is exulting in the success of her treatment regimen, while censuring its cost. Her treatment team, too, earns a mix of kudos and barbs. Comfortable in her lay-expert role and an inveterate listmaker, she draws from the negative encounters to compile pointers for health care professionals:

Don't look horrified when I tell you I have metastatic breast cancer; ... Don't ask me questions about my treatment[s] that are irrelevant to the procedure being performed and/or outside your sphere of knowledge [p 190]

The end of the book is by no means the end of the story or of Kingston's brand of shared wisdom on life after a cancer diagnosis.

As I write this review, her online entries continue, at notjustaboutcancer.blogspot.com.
Sharon Batt MA

Doctoral candidate

Department of Bioethics

Dalhousie University

Halifax, NS

\section{REFERENCES}

1. Burney F. The Journals and Letters of Fanny Burney (Mme D'Arblay). Oxford (UK): Clarendon Press; 1975. p. 596-616.

2. Moore A, Stilgoe J. Experts and anecdotes: the role of "anecdotal evidence" in public scientific controversies. Sci Technol Human Values 2009; pp. 0162243908329382v1.

Batt wrote Patient No More: the Politics of Breast Cancer following her breast cancer diagnosis in 1988. 